\title{
The comparative study among different fractions of muscadine grape 'Noble' pomace extracts regarding anti-oxidative activities, cell cycle arrest and apoptosis in breast cancer
}

\author{
Jianming Luo ${ }^{\mathrm{a}, \mathrm{b}, \mathrm{c}}$, Shiren Song $\mathbb{1}^{\mathrm{a}}$, Zheng Wei $\mathbb{C}^{\mathrm{b}, \mathrm{d}}$, Yu Huang ${ }^{\mathrm{d}}$, Yali Zhang ${ }^{\mathrm{b}}$ and Jiang Lu $^{\mathrm{a}, \mathrm{d}}$ \\ ${ }^{a}$ Center for Viticulture and Enology, School of Agriculture and Biology, Shanghai Jiao Tong University, Shanghai, China; ${ }^{\mathrm{b} T h e ~ V i t i c u l t u r e ~ a n d ~}$ \\ Enology Program, College of Food Science and Nutritional Engineering, China Agricultural University, Beijing, China; 'Department of Food \\ Science and Engineering, Jinan University, Guangzhou, Guangdong, China; ${ }^{d}$ Guangxi Crop Genetic Improvement and Biotechnology Key \\ Lab, Guangxi Academy of Agricultural Science, Guangxi, China
}

\begin{abstract}
As a by-product of wine making, pomace contains rich amounts of phenolic compounds that can be potentially utilized as raw materials to make beneficial products especially for the anti-cancer agents including the breast cancer. Muscadinia rotundifolia 'Noble' is a wine-making grape cultivar, and to better use 'Noble' pomace, the most effective phenolic fractions in cancer inhibition must be identified. In this study, anti-oxidative activities of three separated fractions of 'Noble' pomace (F1, F2 and F3) were compared in 2,2-diphenyl-1-picrylhydrazyl and 2,2'-azino-bis-(3-ethylbenzothiazoline-6-sulphonic acid) radical scavenging (DPPH and ABTS) assays as well as the ferric-reducing antioxidant power (FRAP) assay. The ability of different fractions to induce cell cycle arrest and apoptosis in MDA-MB-231 breast cancer cells was also evaluated by flow cytometry and Western blot analysis. Fraction F3, which contained a mixture of anthocyanidins and ellagic acids, exhibited the strongest anti-oxidative activity, as determined at both low and high concentrations in the DPPH and FRAP assays. F3 also demonstrated the greatest ability to induce apoptosis via caspase activation and cell cycle arrest by downregulating cyclin A and upregulating p21. F3 was thus the most effective bioactive fraction among those prepared from muscadine grape 'Noble' pomace.
\end{abstract}

ARTICLE HISTORY

Received 28 August 2017

Accepted 29 November 2017

\section{KEYWORDS}

Muscadine phenolic fraction; anti-oxidative activity; cell cycle arrest; apoptosis;

cyclin; caspase

\section{Introduction}

Breast cancer, the leading cancer diagnosed in women worldwide, is also the most frequent cause of cancer mortality in many countries [1]. MDA-MB-231, one of the breast cancer cell lines commonly used in cancer research, normally has poor prognosis [2]. It is reported that, the combination treatment of phenolic compounds from plant such as resveratrol together with melphalan could inhibit MDA-MB-231 cells more efficiently [3]. Hence, natural phenolics had a great potential to be the anti-cancer agents.

Muscadinia rotundifolia Michx., also known as the muscadine grape, is indigenous to the southeastern region of the United States [4]. Previous studies have demonstrated that this grape confers multiple health benefits to humans, including cancer inhibition $[5,6]$, a function that is primarily attributed to phenolic compounds [7]. Recently, several varieties of muscadine grapes were introduced to South China, and they adapted well to the climate [8]. One of these varieties,
'Noble', is a cultivar used for wine making $[9,10]$. As the by-product of wine-making, pomace still contains rich amounts of phenolic compounds. Thus, its use as the raw material is potentially beneficial for the production of health products especially for anti-cancer agents. The composition of pomace crude extract is complex, resulting in limited beneficial effects when directly applied. However, if the crude extract is fractionated and the most useful and effective phenolic fraction is identified, it would be possible to develop or improve downstream products utilizing only the most useful fraction. Thus, it is very important to identify the most effective phenolic fraction in a comparative study.

In previous reports, researchers found variable abilities to inhibit colon cancer among fractions from muscadine grape $[11,12]$, although the analysis was limited only to the phenolic fractions or EA-rich fractions derived from fresh grape skin and/or pulp excluding extracts from seeds. On the other aspects, the antioxidative activity, the cell cycle arrest, and the

CONTACT Jiang Lu jiang.lu@sjtu.edu.cn $\Theta$ Center for Viticulture and Enology, School of Agriculture and Biology, Shanghai Jiao Tong University, Shanghai, China

(c) 2017 The Author(s). Published by Informa UK Limited, trading as Taylor \& Francis Group.

This is an Open Access article distributed under the terms of the Creative Commons Attribution License (http://creativecommons.org/licenses/by/4.0/), which permits unrestricted use, distribution, and reproduction in any medium, provided the original work is properly cited. 
induction of apoptosis in cancer cells were used to evaluate and compare the anti-cancer function exerted by different phenolic fractions [11].

To make better use of muscadine grape pomace as a raw material in production of health beneficial products or anti-cancer agents, it is necessary to evaluate and identify the most effective fraction by comparing their anti-oxidative activities, and abilities to induce cell cycle arrest and apoptosis. This study aims to identify this most effective phenolic fraction in MDAMB-231 breast cancer cell inhibition isolated from muscadine grape 'Noble' pomace extracts.

\section{Materials and methods}

\section{Antibodies and chemicals}

The following antibodies were purchased from Cell Signaling Technology (Danvers, MA, USA): rabbit anti-human primary antibodies against CDK2, p21, cleaved caspase-3, caspase-3, cleaved caspase-7, caspase-7, and cleaved caspase-9; mouse anti-human primary antibodies against caspase-9, cyclin A and GAPDH; and HRP-linked secondary antibody (goat anti-rabbit or horse anti-mouse).

DMEM (Dulbecco's modified Eagle's medium), penicillin-streptomycin solution, phosphate buffered saline, trypsin and non-fat milk powder were purchased from HyClone (Logan, UT, USA). Fetal bovine serum (FBS) was purchased from Thermo Fisher Scientific Gibco, (Carlsbad, CA, USA). Cell Counting Kit-8 (CCK-8) was purchased from Dojindo Molecular Technology, Inc. (Japan). A propidium iodide (PI) staining kit, RIPA lysate, phenylmethanesulfonyl fluoride (PMSF) and a BCA assay kit were purchased from Beyotime Institute of Biotechnology (Shanghai, China). An Annexin V-FITC/PI double staining kit was purchased from Nanjing Jiancheng Bioengineering Institute (Jiangsu, Nanjing, China). TBST (TBS with 0.05\% Tween-20) and ECL reagent were purchased from Beijing Solarbio Science and Technology Co. LTD. (Beijing, China). Bovine serum albumin (BSA), 2,2-diphenyl-1-picrylhydrazyl (DPPH), 2,2'-azino-bis(3-ethylbenzothiazoline-6-sulphonic acid) (ABTS) and dimethyl sulphoxide (DMSO) were purchased from Sigma-Aldrich Corp (St. Louis, Mo., USA).

Fractions from 'Noble' pomace extracts were prepared based on a method described in a previous study [12]. All fractions were dissolved in DMSO. The concentration of fraction 1 (F1) was $30.40 \mathrm{mg}$ of dry weight $(\mathrm{DW}) / \mathrm{mL}, \mathrm{F} 2$ was $16.38 \mathrm{mg} \mathrm{DW} / \mathrm{mL}$ and $\mathrm{F} 3$ was $36.29 \mathrm{mg} \mathrm{DW} / \mathrm{mL}$. The composition of each fraction was analyzed by performing LC-TOF-MS/MS at the original concentration indicated above.

F1 contained $1.60 \mathrm{mg} / \mathrm{mL}$ kaempferol, $2.09 \mathrm{mg} / \mathrm{mL}$ quercetin, $2.47 \mathrm{mg} / \mathrm{mL}$ epicatechin, $3.21 \mathrm{mg} / \mathrm{mL}$ gallic acid and $1.35 \mathrm{mg} / \mathrm{mL}$ ellagic acid (EA). F2 contained $0.65 \mathrm{mg} / \mathrm{mL}$ procyanidins and ellagitannins (ET), which resulted in $7.71 \mathrm{mg} / \mathrm{mL}$ EA after acid hydrolysis. F3 contained $1.56 \mathrm{mg} / \mathrm{mL}$ delphinidin, $0.97 \mathrm{mg} / \mathrm{mL}$ cyanidin, $0.95 \mathrm{mg} / \mathrm{mL}$ petunidin, $1.07 \mathrm{mg} / \mathrm{mL}$ peonidin, $1.20 \mathrm{mg} / \mathrm{mL}$ malvidin and $7.19 \mathrm{mg} / \mathrm{mL}$ EA. These contents, which were determined by multiplying the fraction concentration $(\mathrm{mg} \mathrm{DW} / \mathrm{mL}$ ) by the LC-TOFMS/MS results, were consistent with the fraction contents in our previous report [13].

\section{Breast cancer cell lines and culture}

The breast cancer cell MDA-MB-231 (the Type Culture Collection of the Chinese Academy of Sciences, China) was cultured in DMEM medium supplemented with $10 \%$ FBS and $1 \%$ penicillin-streptomycin solution. Cancer cells were incubated in an incubator with 5\% $\mathrm{CO}_{2}$ at $37^{\circ} \mathrm{C}$. The medium was changed every other day.

\section{Cell viability/inhibition assay}

A cell viability assay was performed using the CCK-8 kit following the manufacturer's protocol. Briefly, $200 \mu \mathrm{L}$ of medium without cells was added into 5 wells of a 96-well, flat-bottom plate (Corning Life Science, Bedford, MA, USA) as the blank group. For other groups, $200 \mu \mathrm{L}$ of a single cell suspension at a density of $5.5 \times 10^{4}$ cells $/ \mathrm{mL}$ was added to the remaining wells of the 96-well plate, which was then incubated in $5 \% \mathrm{CO}_{2}$ at $37^{\circ} \mathrm{C}$. After $24 \mathrm{~h}$, serial concentrations of each fraction were added into each well for each treatment group, while DMSO alone was added to the control group. The final DMSO concentration was $0.25 \%$. After another 24 -h incubation period, the medium was removed from all cells, the cells were washed with PBS, and medium containing $10 \%$ CCK solution was added into each well. After incubation at $37^{\circ} \mathrm{C}$ for $3 \mathrm{~h}$, the absorbance was read at $450 \mathrm{~nm}$ using a Thermo Multiskan Ascent Reader. The concentrations for all fractions were determined in quintuplicate, and each assay was repeated three times.

The inhibitory rate was calculated using the following formula based on cell viability:

$$
\text { Inhibition rate } \begin{aligned}
(\%) & =100 \%-\text { cell viability }(\%) \\
& =[(\mathrm{Ac}-\mathrm{At}) /(\mathrm{Ac}-\mathrm{Ab})] \times 100 \%
\end{aligned}
$$


where Ac is the absorbance of the control group, At is the absorbance of the treatment group, and $\mathrm{Ab}$ is the absorbance of the blank group.

\section{Measurement of anti-oxidative activity}

DPPH, ABTS radical scavenging and ferric-reducing antioxidant power (FRAP) assays were carried out according to procedures described in previous studies $[14,15]$. The absorbance was read at 515, 734 and $593 \mathrm{~nm}$, respectively. For the DPPH and ABTS assays, the inhibition rate of the test sample was calculated using the following formula:

$$
\text { Inhibition }(\%)=\left(\mathrm{A}_{0}-\mathrm{A}\right) / \mathrm{A}_{0} \times 100 \%
$$

where $A_{0}$ was the absorbance of blank (which contained only solvent), and A was the absorbance of the samples.

A calibration curve was established using the inhibition rate and known Trolox solution. All results from these 3 assays were expressed as Trolox equivalent antioxidant capacity $(\mu \mathrm{M} \mathrm{TE} / \mathrm{mL})$.

\section{Cell cycle arrest assay}

This assay was performed using a PI staining kit following the manufacturer's instructions. Briefly, cells from the 24-h treatment group or the control group were harvested. After trypsin digestion and centrifugation at $1000 \mathrm{~g}$ for $8 \mathrm{~min}$, the supernatants were removed, and the remaining cells were washed with pre-cooled PBS solution. The supernatants were discarded after centrifugation at $1000 \mathrm{~g}$ for $10 \mathrm{~min}$. Fixation was performed by adding $70 \%$ pre-cooled ethanol to single cells and incubating at $-20^{\circ} \mathrm{C}$ overnight. The ethanol was removed via centrifugation (at $1000 \mathrm{~g}$ for $10 \mathrm{~min}$ ), and the fixed cells were washed with pre-cooled PBS solution followed by centrifugation at $1000 \mathrm{~g}$ for $10 \mathrm{~min}$. The supernatants were discarded, and the reaction mixture from the kit was added, followed by incubation at $37^{\circ} \mathrm{C}$ for $30 \mathrm{~min}$. The assay results were measured using a flow cytometer and analyzed using Mod Fit LT v 3.2.

\section{Cell apoptosis assay}

This assay was performed using the Annexin V-FITC/ PI double staining kit per the manufacturer's instructions. A single-cell suspension from the treatment group or the control group was prepared via trypsin digestion, centrifugation and pre-cooled PBS washing. The supernatant was discarded, and binding solution was added, followed by addition of Annexin V-FITC solution and PI solution. The mixture was incubated at room temperature for $10 \mathrm{~min}$ in the dark. The assay results were detected by flow cytometry (FCM) and analyzed using FCS Express v 3.0.

\section{Western blot}

A total of $2 \mathrm{~mL}$ of cell suspension with a density of $5.5 \times 10^{4}$ cells $/ \mathrm{mL}$ was incubated in a 6-well, flatbottom plate in $5 \% \mathrm{CO}_{2}$ at $37^{\circ} \mathrm{C}$ for $48 \mathrm{~h}$. Cells were then treated with 3 different fractions at different concentrations and incubated for another $24 \mathrm{~h}$. Cells were lysed in RIPA lysate buffer containing $1 \mathrm{mM}$ PMSF, which had been used in many other reports [16-18]. The cell lysates were centrifuged, the supernatants were collected and protein concentration was quantified using a BCA assay kit. The concentrations of total protein were normalized based on the results of the BCA assay. The same volume of cell lysate was resolved on a $12 \%$ SDS-PAGE gel, followed by trans-blotting onto nitrocellulose membranes. After trans-blotting, membranes were blocked in TBST containing 5\% non-fat milk. The blocked membranes were then incubated with properly diluted primary antibodies in TBST containing either $5 \%$ non-fat milk or $5 \%$ BSA (following the instructions provided) at $4^{\circ} \mathrm{C}$ overnight. The membranes were then washed three times with TBST and incubated in appropriately diluted HRPlinked secondary antibodies in TBST containing 5\% non-fat milk at room temperature for $1 \mathrm{~h}$. Membranes were washed with TBST another three times and visualized using ECL reagent.

\section{Statistical analysis}

Results were expressed as the mean \pm standard deviation. All data were statistically analyzed by one-way ANOVA using SPSS v20.0. Significant differences were determined when $p<0.05$ (Duncan's test).

\section{Results and discussion}

\section{Determination of cell inhibitory concentrations among fractions}

A pilot study had been done to confirm the solvent $(0.25 \%$ DMSO $)$ did not affect the cell viability. After treating cancer cells with each fraction extracted from 'Noble' pomace, the highest growth inhibition rates were $86.7 \%, 92.9 \%$ and $92.6 \%$ for $\mathrm{F} 1, \mathrm{~F} 2$ and $\mathrm{F} 3$, respectively (Figure 1 ). Two different cell inhibitory concentrations, $\quad \mathrm{IC}_{80} \quad(80 \%$ maximal inhibitory 


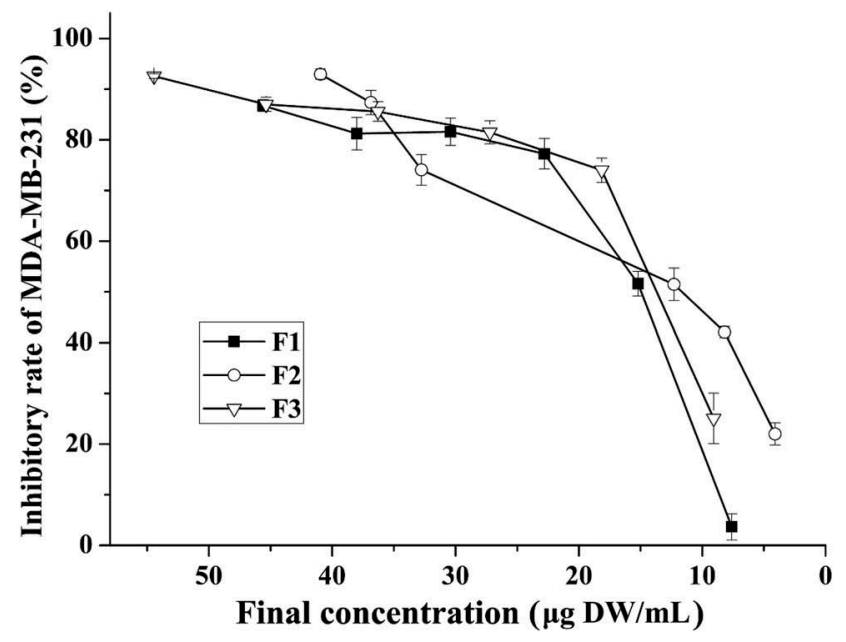

Figure 1. Inhibition rates for MDA-MB-231 cells after treatment with isolated fractions of 'Noble' pomace. F1: mixture of flavonoids, phenolic acids and EA; F2: mixture of tannins; F3: mixture of anthocyanidins and EA.

Table 1. $80 \%$ and $50 \%$ maximum inhibitory concentrations of different fractions.

\begin{tabular}{lcc}
\hline & \multicolumn{2}{c}{ Concentration $(\mu \mathrm{g} \mathrm{DW} / \mathrm{mL})$} \\
\cline { 2 - 3 } Group & $\mathrm{IC}_{50}$ (low concentration) & $\mathrm{IC}_{80}$ (high concentration) \\
\hline F1 & $17.82 \pm 2.42^{\mathrm{a}}$ & $29.64 \pm 1.50^{\mathrm{a}}$ \\
F2 & $9.75 \pm 0.52^{\mathrm{b}}$ & $20.85 \pm 2.37^{\mathrm{b}}$ \\
F3 & $12.88 \pm 2.69^{\mathrm{ab}}$ & $25.00 \pm 1.73^{\mathrm{ab}}$ \\
\hline
\end{tabular}

F1: mixture of flavonoids, phenolic acids and EA; F2: mixture of tannins; F3: mixture of anthocyanidins and EA. The same letter in the same column indicates no significant differences $(p \geq 0.05)$.

concentration) and $\mathrm{IC}_{50}(50 \%$ maximal inhibitory concentration), of each fraction were calculated based on the inhibition curve. The $\mathrm{IC}_{80}$ and $\mathrm{IC}_{50}$ values of $\mathrm{F} 2$ were $20.85 \pm 2.37$ and $9.75 \pm 0.52 \mu \mathrm{g} \mathrm{DW} / \mathrm{mL}$, respectively. These values were significantly lower than those of $\mathrm{F} 1$ in which the $\mathrm{IC}_{80}$ was $29.64 \pm 1.50 \mu \mathrm{g} \mathrm{DW} / \mathrm{mL}$ and the $\mathrm{IC}_{50}$ was $17.82 \pm 2.42 \mu \mathrm{g} \mathrm{DW} / \mathrm{mL}$, but they were similar to those for $\mathrm{F} 3$, which was $25.00 \pm 1.73$ and $12.88 \pm 2.69 \mu \mathrm{g} \mathrm{DW} / \mathrm{mL}$ for $\mathrm{IC}_{80}$ and $\mathrm{IC}_{50}$, respectively (Table 1).

Lower $\mathrm{IC}_{50}$ and $\mathrm{IC}_{80}$ values indicated a stronger capacity for cell growth inhibition. Based on the above results, similar $\mathrm{IC}_{50}$ and $\mathrm{IC}_{80}$ values were obtained for F2 and F3. Thus, identifying the most effective fraction only by comparing the values of these two inhibitory concentrations was not sufficient, the anti-oxidative activity as well as the ability to induce cell cycle arrest and apoptosis which were used for the evaluation of the anti-cancer function exerted by phenolic compounds [11], should also be compared after treating the cells with $\mathrm{IC}_{80}$ (high concentration) and $\mathrm{IC}_{50}$ (low concentration).

\section{Anti-oxidative activities among fractions}

The anti-oxidative activities among the 3 fractions varied in both low and high concentrations (Table 2). In $\mathrm{DPPH}$ assay, F3 showed a value of $4.44 \pm 0.38$ and $2.33 \pm 0.18 \mu \mathrm{M} \mathrm{TE} / \mathrm{mL}$ for high and low concentrations, and both of these figures were the highest values among all fractions. No difference was found in the anti-oxidative activities between F1 and F2. Similarly in FRAP assay, F3 presented a value of $5.87 \pm 0.09 \mu \mathrm{M}$ $\mathrm{TE} / \mathrm{mL}$ for high and $2.94 \pm 0.05 \mu \mathrm{M} \mathrm{TE} / \mathrm{mL}$ for low concentration treatments, which also indicated the strongest anti-oxidative activity among the three fractions. However, at both concentrations, the results from the ABTS assay did not significantly differ among all the fractions. Different values are obtained for different assays because each method has multiple reaction characteristics and mechanisms [19]. Therefore, to obtain a more accurate picture of antioxidative activity, it is preferable to evaluate activity in multiple assays.

\section{Ability to induce cell cycle arrest as determined by FCM}

After treating cells with fractions of 'Noble' pomace extract in either low or high concentration, proportions of cell populations in the G0/G1, S and G2/M phases changed drastically in each group at varied extents (Figure 2).

Treatment with low concentrations of F1, F2 and F3 caused $30.28 \%, 34.13 \%$ and $33.16 \%$ of cells to be arrested in S phase, while in the control there were $18.22 \%$ cells in the $S$ phase. These results indicate that F1 induced the lowest amount of S phase arrest, while F2 and F3, with no difference between them, resulted in higher percentages of cells arrested in S phase. In high concentrations, treatment with $\mathrm{F} 1$ resulted in a

Table 2. Anti-oxidative activities of different fractions at low and high concentrations.

\begin{tabular}{|c|c|c|c|c|c|c|}
\hline & \multicolumn{2}{|c|}{ DPPH $(\mu \mathrm{M}$ TE/mL) } & \multicolumn{2}{|c|}{ ABTS $(\mu \mathrm{M}$ TE/mL) } & \multicolumn{2}{|c|}{ FRAP $(\mu \mathrm{M}$ TE/mL) } \\
\hline & Low conc. & High conc. & Low conc. & High conc. & Low conc. & High conc. \\
\hline F1 & $1.34 \pm 0.20^{b}$ & $2.27 \pm 0.34^{b}$ & $2.33 \pm 0.25^{\mathrm{a}}$ & $3.95 \pm 0.42^{\mathrm{a}}$ & $2.37 \pm 0.21^{b}$ & $4.01 \pm 0.36^{b}$ \\
\hline $\mathrm{F} 2$ & $1.24 \pm 0.31^{b}$ & $2.63 \pm 0.65^{b}$ & $1.91 \pm 0.42^{\mathrm{a}}$ & $4.06 \pm 0.90^{\mathrm{a}}$ & $2.16 \pm 0.06^{b}$ & $4.60 \pm 0.13^{b}$ \\
\hline F3 & $2.23 \pm 0.18^{a}$ & $4.44 \pm 0.38^{a}$ & $2.57 \pm 0.14^{a}$ & $5.13 \pm 0.27^{a}$ & $2.94 \pm 0.05^{\mathrm{a}}$ & $5.87 \pm 0.09^{a}$ \\
\hline
\end{tabular}

Low conc.: low concentration; High conc.: high concentration. F1: mixture of flavonoids, phenolic acids and EA; F2: mixture of tannins; F3: mixture of anthocyanidins and EA. The same letter in the same column indicates no significant differences $(p \geq 0.05)$. 

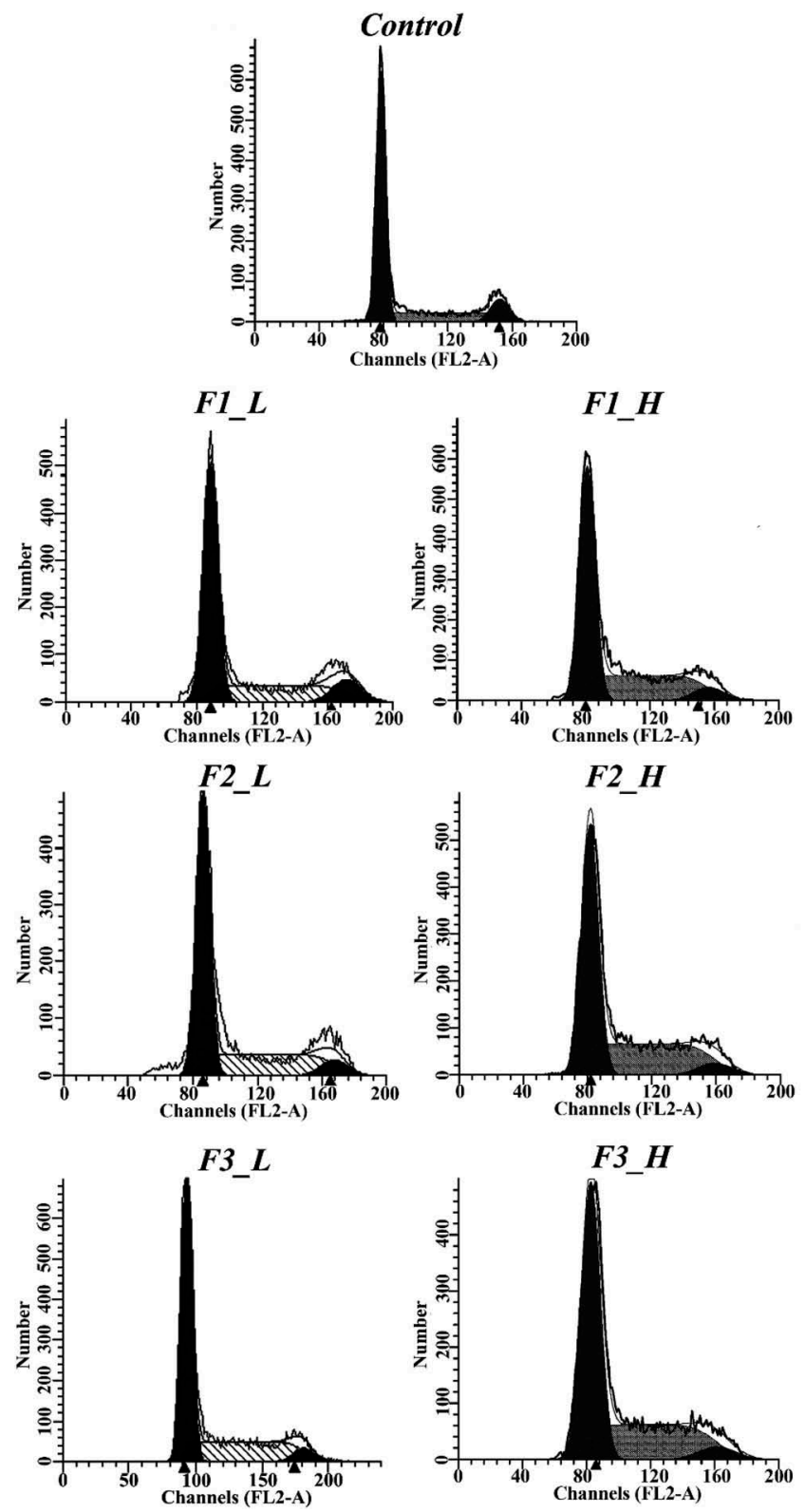

Figure 2. Plots from the cell cycle arrest assay using different fractions at low and high concentrations. Control: solvent treatment; F1 (F2, F3)_L: low concentrations of F1 (F2, F3); F1 (F2, F3)_H: high concentrations of F1 (F2, F3).

significantly higher proportion (36.88\%) of cells retarded in S phase than the control (18.22\%), and even stronger $\mathrm{S}$ phase arrests were found in F2 and
F3 treatments where $40.28 \%$ and $39.66 \%$ of cells were trapped in $S$ phase (Table 3).

Based on the FCM measurement on cell cycle arrests, fraction F2 had the strongest ability to cause $\mathrm{S}$ phase arrest, followed by F3 and F1. Interestingly, the ability to induce cell cycle arrest in $S$ phase coincides with the EA content in each fraction. Although F2 is primarily composed of ETs, it was previously demonstrated that ETs must first be hydrolyzed into EA to be functional and cause $S$ phase arrest in prostate cancer cells [20]. According to the results of our current study, as well as those in the previous report, the ability to induce cell cycle arrest may be attributable to the EA content within each fraction. Notably, there was a similar effect exerted on $\mathrm{S}$ phase arrest by the F2 and F3 fractions at both concentrations, also indicating that treatment with the F3 fraction efficiently induces cell cycle arrest.

\section{Comparison of cell cycle arrest by Western blot analysis}

Cyclin A, CDK2 and p21 were tested to determine which fraction presented the strongest ability to induce cell cycle arrest at the protein level. As shown in Figure 3, after treating the cells with muscadine fractions at low concentrations, cyclin A expression levels in all treatment groups were at least 2 times lower than those in the control group, as measured by the integrated densities of Western blot bands. Among them, the treatment with F2 induced significantly lower expression of cyclin A than treatment with F3 and F1, which exerted similar effects on cyclin A down-regulation. At high concentrations, treatment with all fractions, and particularly $\mathrm{F} 2$ and F3, induced much stronger down-regulation of cyclin A expression. Cyclin A down-regulation was affected in the following order: F2 exerted the strongest effects, followed by F3 (similar to F2 at high concentration) and then F1. Additionally, at low concentrations, no statistical differences were observed on expression of the p21 protein among three treatments. But at high concentrations, different treatments induced different

Table 3. Proportion of cells in different cell cycle phases after treatment with different fractions at high and low concentration (mean \pm standard deviation).

\begin{tabular}{lllrrr}
\hline & & \multicolumn{3}{c}{ Group } \\
\cline { 3 - 6 } Phase & Concentration & Control & F1 & F2 & F3 \\
\hline G0/G1 & Low & $67.17 \pm 0.52^{\mathrm{a}}$ & $59.50 \pm 0.21^{\mathrm{b}}$ & $58.49 \pm 0.13^{\mathrm{c}}$ & $60.25 \pm 0.13^{\mathrm{b}}$ \\
& High & $67.17 \pm 0.52^{\mathrm{a}}$ & $56.90 \pm 0.34^{\mathrm{b}}$ & $54.21 \pm 1.50^{\mathrm{c}}$ & $55.20 \pm 0.06^{\mathrm{bc}}$ \\
$\mathrm{S}$ & Low & $18.22 \pm 0.07^{\mathrm{c}}$ & $30.28 \pm 0.22^{\mathrm{b}}$ & $34.13 \pm 0.38^{\mathrm{a}}$ & $33.16 \pm 0.71^{\mathrm{a}}$ \\
& High & $18.22 \pm 0.07^{\mathrm{c}}$ & $36.88 \pm 0.21^{\mathrm{b}}$ & $40.28 \pm 0.80^{\mathrm{a}}$ & $39.66 \pm 0.13^{\mathrm{ab}}$ \\
$\mathrm{G} 2 / \mathrm{M}$ & Low & $14.61 \pm 0.48^{\mathrm{a}}$ & $10.22 \pm 0.64^{\mathrm{b}}$ & $7.38 \pm 0.31^{\mathrm{c}}$ & $6.58 \pm 0.22^{\mathrm{c}}$ \\
& High & $14.61 \pm 0.48^{\mathrm{a}}$ & $6.32 \pm 0.04^{\mathrm{b}}$ & $5.52 \pm 0.63^{\mathrm{b}}$ & $5.15 \pm 0.17^{\mathrm{b}}$ \\
\hline
\end{tabular}

F1: mixture of flavonoids, phenolic acids and EA; F2: mixture of tannins; F3: mixture of anthocyanidins and EA. The same letter in the same row indicates no significant differences $(p \geq 0.05)$. 
(a)

CDK2

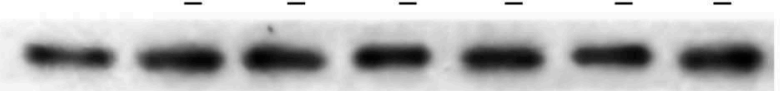

(b)

GAPDH
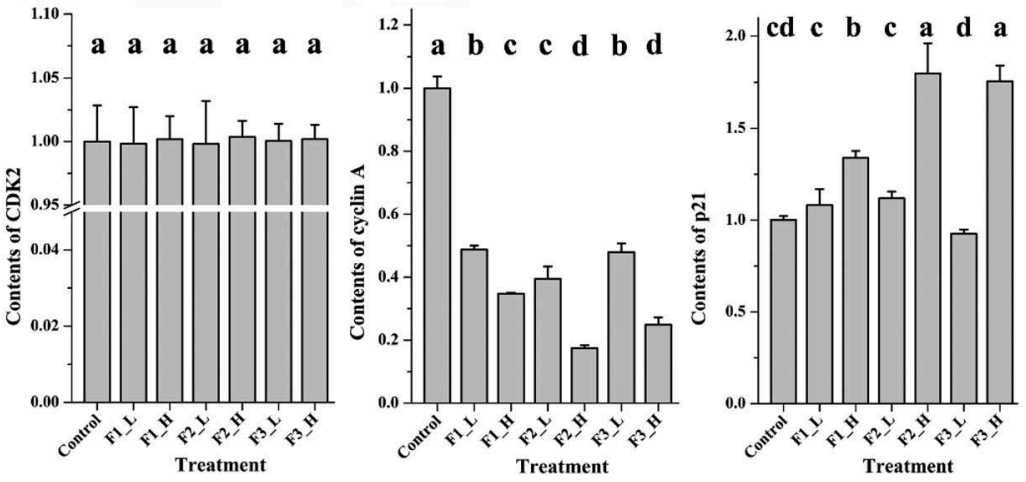

Figure 3. Expression of cell cycle arrest proteins following treatment with different fractions at high or low concentrations. (a) Bands obtained from Western blot analysis; (b) bar charts of the mean integrated density of each band over the corresponding integrated density of GAPDH (control value adjusted to 1). 'a, b, $c^{\prime}$ : the same letter above the bars indicates no significant differences ( $\left.p \geq 0.05\right)$. Control: solvent treatment; F1 (F2, F3)_L: low concentrations of F1 (F2, F3); F1 (F2, F3)_H: high concentrations of F1 (F2, F3).

expressing levels of p21 protein. A higher level of p21 protein was obtained in treatments F2 and F3 than in treatment F1. This result strongly supports the FCM cell cycle analysis. Expression of the cytokine CDK2, on the other hand, remains unchanged in all treatment groups regardless of the fraction concentrations.

Formation of the CDK2/cyclin A complex is crucial for cells to pass through $S$ phase and enter G2/M phase [21]. Therefore, the down-regulation of either cytokine causes cells to accumulate in $S$ phase, resulting in $S$ phase arrest. The cytokine p21 is an inhibitor of CDK2 and binds to the CDK2/cyclin E complex to induce G1 arrest [22-25], but it has also been reported to induce $S$ phase arrest [26]. Since no significant changes in CDK2 expression was measured in the current study, the ability of F2 and F3 to induce the down-regulation of cyclin A and up-regulation of p21 expression especially at high concentration made it the most effective fraction for inducing $S$ phase arrest.

\section{Ability to induce apoptosis as determined by FCM}

Following treatments of cells with fractions of 'Noble' pomace extracts in either low or high concentrations, the proportions of normal and apoptotic cells varied (Figure 4). Only $0.40 \%$ of the total cells were apoptotic in the control group, while treatments with F1, F2 and F3 at low concentrations increased the apoptotic cells by $9.63 \%, 6.07 \%$ and $11.63 \%$, respectively. Higher percentages of apoptotic cells were observed in all 3 fractions in the treatments with higher concentrations (Table 4). In general, treatment with fraction F3 induced the significantly highest numbers of apoptotic cells in both concentrations, followed by F1 and then F2.

F3 is primarily composed of monomers with high bioavailability, such as anthocyanins, while fraction F2 contains polymers such as ETs and procyanidins. ETs belong to the family of hydrolysable tannins, which are hydrolyzed into EA, but the procyanidins, which belong to the condensed tannin family, are stable and have relatively low bioavailability [27]. Therefore, the ability to induce apoptosis is more likely to be related to the bioavailability of phenolic compounds.

\section{Comparison of apoptosis induction by Western blot analysis}

Caspases, an important group of enzymes belonging to the cysteine protease family, are crucial for apoptosis. The cleavage of pro-caspase into cleaved caspase indicates the activation and initiation of degradation of chromosomal DNA as well as nuclear and cytoskeletal 

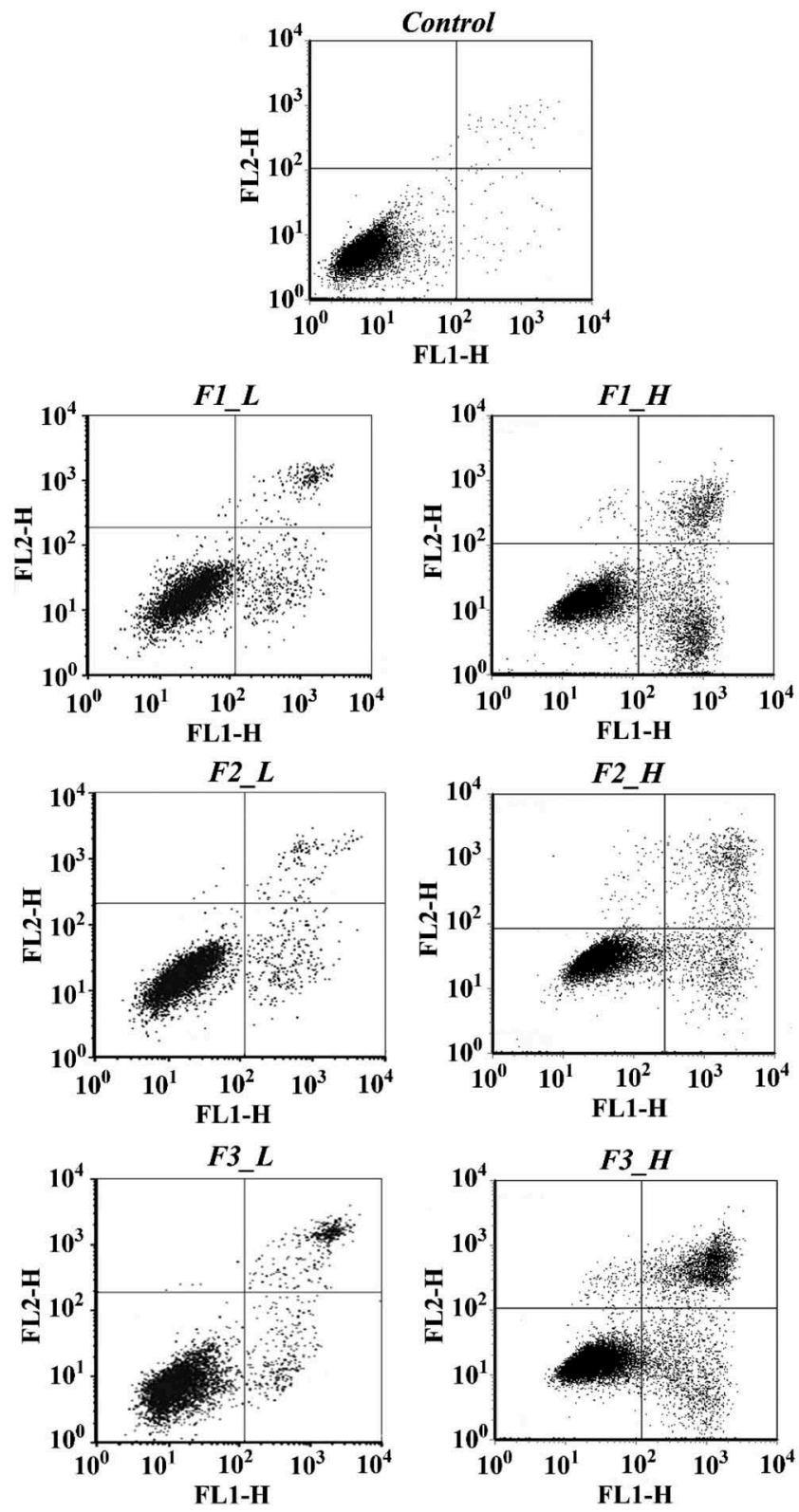

Figure 4. Plots from the cell apoptosis assay for different fractions at low and high concentrations. Control: solvent treatment; F1 (F2, F3)_L: low concentrations of F1 (F2, F3); F1 (F2, F3)_H: high concentrations of F1 (F2, F3).

proteins [28]. Three caspase family members, caspase$3,-9$ and -7 , either in their pro- or cleaved forms, were detected by Western blot to determine which fraction had the strongest ability to induce apoptosis at the protein level. As shown in Figure 5, the expression of pro-caspase-3 was reduced while the corresponding cleaved proteins were raised significantly after treatment with F3 at both low and high concentrations. This result indicated that F3 could activate the caspase-3, and the higher of the treating concentration, the more activated form of caspase- 3 was found. Similar results were also obtained from caspase- 9 and caspase-7. The treatment with F2 and F1 also activated 3 types of caspases, but much weaker effect was observed.

Caspase- 3 is the most important executioner caspase, directly activating associated endonucleases and proteases and leading to the degradation of chromosomal DNA, as well as nuclear and cytoskeletal proteins [28]. Caspase-9 lies upstream of caspase- 3 and is considered the key initiator caspase of the intrinsic apoptotic pathway [29]. Moreover, caspase-7 is a type of executioner caspase with high similarity to caspase- 3 [30]. It has been reported that, both anthocyanidins and ellagic acid induced apoptosis in multiple types of cancer cell lines via activating the caspases [31-34]. Therefore, the increased cleavage of all 3 caspases following treatment with F3, which contained a mixture of anthocyanidins and ellagic acid, would result in its strongest ability for apoptosis induction.

\section{Conclusion}

Based on the results of the present study, fraction F3, which contained a mixture of anthocyanidins and EA, exhibited the strongest anti-oxidative activity. In comparison with F1 and F2 fractions, F3 also exhibited the strongest ability to induce apoptosis and cell cycle arrest. This was likely attributable to the ability of F3 more effectively activating caspase-3, -7 and -9, and more efficiently inducing $\mathrm{S}$ phase arrest by down-regulating the expression of cyclin A and up-regulating the expression of p21. The results indicated that $\mathrm{F} 3$ is the most effective fraction in breast cancer cell MDA-MB-231 inhibition among the three fractions prepared from muscadine grape 'Noble' pomace.

Table 4. Proportions of normal and apoptotic cells after treatment with different fractions at high and low concentrations (mean \pm standard deviation).

\begin{tabular}{llrrrr}
\hline & & \multicolumn{3}{c}{ Group } \\
\cline { 2 - 6 } Cell & Concentration & Control & F1 & F2 & F3 \\
\hline Normal & Low & $99.24 \pm 0.17^{\mathrm{a}}$ & $89.85 \pm 0.45^{\mathrm{c}}$ & $93.45 \pm 0.32^{\mathrm{b}}$ & $87.91 \pm 0.13^{\mathrm{d}}$ \\
& High & $99.24 \pm 0.17^{\mathrm{a}}$ & $79.17 \pm 0.11^{\mathrm{c}}$ & $87.15 \pm 0.11^{\mathrm{b}}$ & $77.14 \pm 0.16^{\mathrm{d}}$ \\
Apoptotic & Low & $0.40 \pm 0.08^{\mathrm{d}}$ & $10.03 \pm 0.37^{\mathrm{b}}$ & $6.47 \pm 0.63^{\mathrm{c}}$ & $12.03 \pm 0.63^{\mathrm{a}}$ \\
& High & $0.40 \pm 0.08^{\mathrm{d}}$ & $19.63 \pm 0.48^{\mathrm{b}}$ & $11.99 \pm 0.50^{\mathrm{c}}$ & $21.52 \pm 0.58^{\mathrm{a}}$ \\
\hline
\end{tabular}

F1: mixture of flavonoids, phenolic acids and EA; F2: mixture of tannins; F3: mixture of anthocyanidins and EA. The same letter in the same row indicates no significant differences $(p \geq 0.05)$. 
(a)
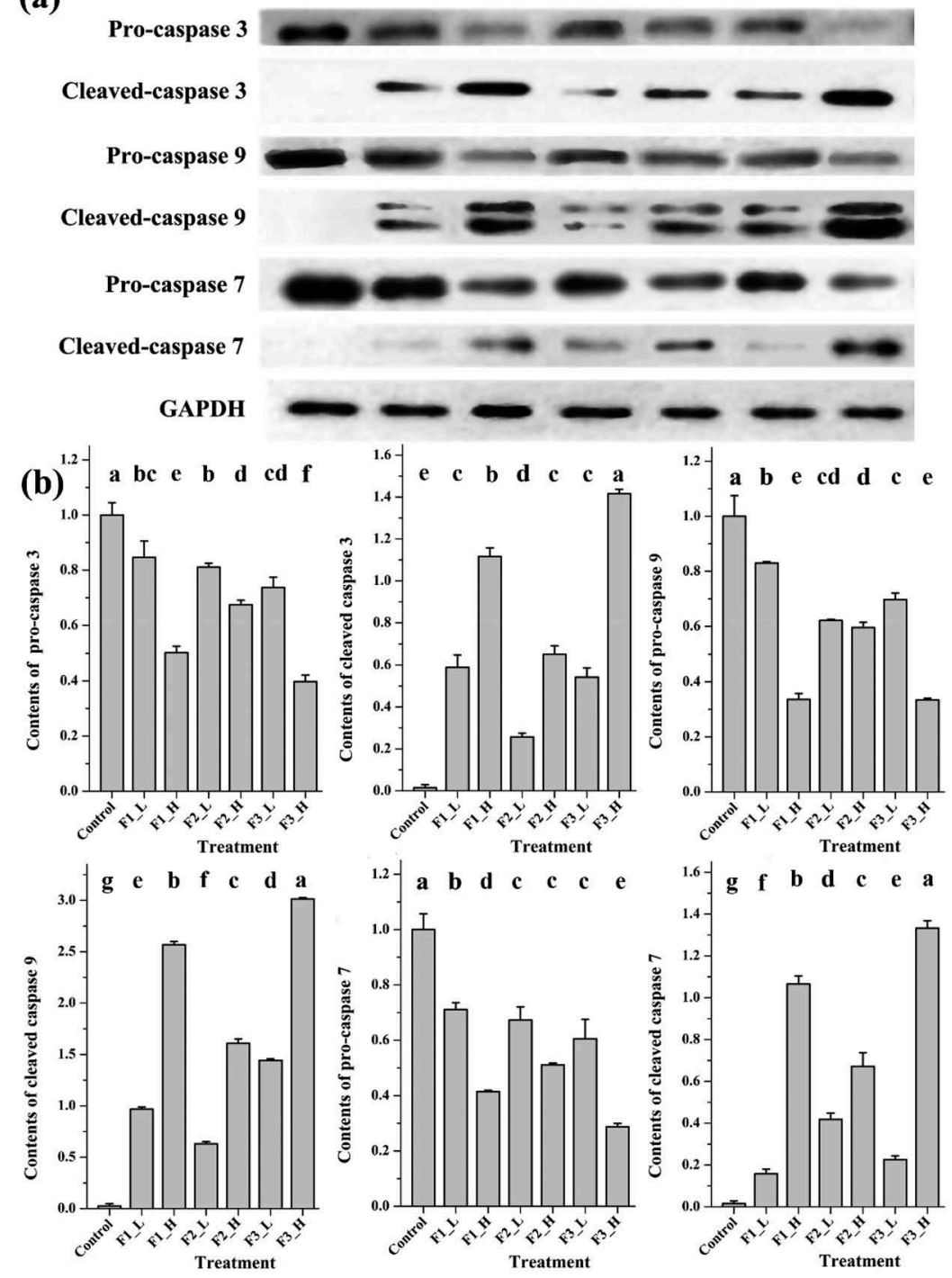

Figure 5. Contents of apoptosis proteins following treatment with different fractions at high or low concentrations. (a) Bands obtained from Western blotting; (b) bar charts of the mean integrated density of each band over the corresponding integrated density of GAPDH (control value adjusted to 1). 'a, b, $c$ ': the same letter above the bars indicates no significant differences $(p \geq 0.05)$. Control: solvent treatment; F1 (F2, F3)_L: low concentrations of F1 (F2, F3); F1 (F2, F3)_H: high concentrations of F1 (F2, F3).

\section{Author contributions}

Jianming Luo conceived, designed, and carried out the experiments, collected and analyzed the data and wrote the manuscript. Zheng Wei and Yu Huang prepared the samples. Yali Zhang and Shiren Song evaluated the study. Jiang Lu designed the overall research plan, monitored and evaluated the research progress, supervised and participated in the manuscript preparation.

\section{Acknowledgments}

This work was supported by the China Agriculture Research System (grant no. CARS-30-yz-2); and Bagui Scholar Fund of Guangxi, China ([2013]3). This work was partially funded by the Dongguan Research \& Entrepreneurship Talent Reward Program.

\section{Disclosure statement}

No potential conflict of interest was reported by the authors.

\section{Funding}

This work was supported by the Bagui Scholar Fund of Guangxi, China [[2013]3]; China Agriculture Research System [CARS-30-yz-2].

\section{ORCID}

Shiren Song (i) http://orcid.org/0000-0002-1343-6781

Zheng Wei (1) http://orcid.org/0000-0003-4008-2496 


\section{References}

[1] Schnitt SJ, Lakhani SR. Breast cancer. In: Stewart BW, Wild CP, editors. World cancer report 2014 (pp. 362363). Geneva: WHO Press; 2014.

[2] Cheanf MC, Voduc D, Bajdik C, et al. Basal-like breast cancer defined by five biomarkers has superior prognostic value than triple-negative phenotype. Clin Cancer Res. 2008;14:1368-1376.

[3] Casanova F, Quarti J, da Costa DC, et al. Resveratrol chemosensitizes breast cancer cells to melphalan by cell cycle arrest. J Cell Biochem. 2012;113:2586-2596.

[4] Conner PJ. Characteristics of promising muscadine grape (Vitis rotundifolia Michx.) selections from the University of Georgia (USA) breeding program. Acta Horticul. 2014;1046:303-307.

[5] Burton LJ, Smith BA, Smith BN, et al. Muscadine grape skin extracts can antagonize Snial-cathepsin L-mediated invasion, migration and osteoclastogenesis in prostate and breast cancer cells. Carcinogenesis. 2015;36:1019-1027.

[6] Paller CJ, Rudek MA, Zhou XC, et al. A phase I study of muscadine grape skin extract in men with biochemically recurrent prostate cancer: safety, tolerability, and dose determination. Prostate. 2015;75:1518-1525.

[7] Yang CS, Landau JM, Huang MT, et al. Inhibition of carcinogenesis by dietary polyphenolic compounds. Annu Rev Nutr. 2001;21:381-406.

[8] Wei Z, Luo J, Huang Y, et al. Profile of polyphenol compounds of five muscadine grapes cultivated in the United States and in newly adapted locations in China. Int J Mol Sci. 2017;18:631.

[9] Lamikanra O. Changes in organic acid composition during fermentation and aging of Noble muscadine wine. J Agr Food Chem. 1997;45:935-937.

[10] Lamikanra O, Grimm CC, Inyang ID. Formation and occurrence of flavor components in Noble muscadine wine. Food Chem. 1996;56:373-376.

[11] Mertens-Talcott SU, Lee J-H, Percival SS, et al. Induction of cell death in Caco-2 human colon carcinoma cells by ellagic acid rich fractions from muscadine grapes (Vitis rotundifolia). J Agr Food Chem. 2006;54:5336-5343.

[12] Yi W, Fischer J, Akoh CC. Study of anticancer activities of muscadine grape phenolics in vitro. J Agr Food Chem. 2005;53:8804-8812.

[13] Luo J, Zheng W, Zhang S, et al. Phenolic fractions from muscadine grape "Noble" pomace can inhibit breast cancer cell MDA-MB-231 better than those from European grape "Cabernet Sauvignon" and induce S-phase arrest and apoptosis. J Food Sci. 2017;82:1254-1263.

[14] Xu C, Zhang Y, Cao L, et al. Phenolic compounds and antioxidant properties of different grape cultivars grown in China. Food Chem. 2010;119:1557-1565.

[15] Benzie IFF, Strain JJ. The ferric reducing ability of plasma (FRAP) as a measure of "antioxidant power": the FRAP assay. Anal Biochem. 1996;239:70-76.

[16] Tong J, Mo Q-G, Ma B-X, et al. The protective effects of Cichorium glandulosum seed and cynarin against cyclophosphamide and itsmetabolite acrolein-induced hepatotoxicity in vivo and in vitro. Food Funct. 2017;8(1):209-219.

[17] Zhang X, Yang J, Yu X, et al. Angiotensin II-induced early and late inflammatory responses through NOXs and MAPK pathways. Inflammation. 2017;40(1):154-165.
[18] Guo J, Hao J, Jiang H, et al. Proteasome activator subunit 3 promotes pancreatic cancer growth via c-Mycglycolysis signaling axis. Cancer Lett. 2017;386:161-167.

[19] Di Majo D, Giammanco M, La Guardia M, et al. Flavanones in citrus fruit: structure-antioxidant activity relationships. Food Res Int. 2005;38:1161-1166.

[20] Vicinanza R, Zhang Y, Henning SM, et al. Pomegranate juice metabolites, ellagic acid and urolithin A, synergistically inhibit androgen-independent prostate cancer cell growth via distinct effects on cell cycle control and apoptosis. Evid-Based Compl Alt. 2013;2013:1-12.

[21] Lee JI, Kim I-H, Nam T-J. Crude extract and solvent fractions of Calystegia soldanella induce G1 and S phase arrest of the cell cycle in HepG2 cells. Int J Oncol. 2017;50:414-420.

[22] Cooper GM, Hausman RE. The cell cycle. In: The cell: a molecular approach. 4th ed. Washington (DC): ASM Press; 2007. p. 650-668.

[23] Agarwal C, Sharma Y, Zhao J, et al. A polyphenolic fraction from grape seeds causes irreversible growth inhibition of breast carcinoma MDA-MB468 cells by inhibiting mitogen-activated protein kinases activation and inducing G1 arrest and differentiation. Clin Cancer Res. 2000;6:2921-2930.

[24] Kaur M, Mandair R, Agarwal R, et al. Grape seed extract induces cell cycle arrest and apoptosis in human colon carcinoma cells. Nutr Cancer. 2008;60:2-11.

[25] Kaur M, Tyagi A, Singh RP, et al. Grape seed extract upregulates p21 (Cip1) through redox-mediated activation of ERK1/2 and posttranscriptional regulation leading to cell cycle arrest in colon carcinoma HT29 cells. Mol Carcinogen. 2011;50:553-562.

[26] Radhakrishnan SK, Feliciano CS, Najmabadi F, et al. Constitutive expression of E2F-1 leads to p21-dependent cell cycle arrest in $\mathrm{S}$ phase of the cell cycle. Oncogene. 2004;23:4173-4176.

[27] Rasmussen SE, Frederiksen H, Krogholm KS, et al. Dietary proanthocyanidins: occurrence, dietary intake, bioavailability, and protection against cardiovascular disease. Mol Nutr Food Res. 2005;49:159-174.

[28] Elmore S. Apoptosis: a review of programmed cell death. Toxicol Pathol. 2007;35:495-516.

[29] Saelens X, Festjens N, Vande Walle L, et al. Toxic proteins released from mitochondria in cell death. Oncogene. 2004;23:2861-2874.

[30] Cohen GM. Caspases: the executioners of apoptosis. Biochem J. 1997;326:1-16.

[31] Yan X, Wu L, Li B, et al. Cyanidin-3-O-glucoside induces apoptosis and inhibits migration of tumor necrosis factor- $\alpha$-treated rat aortic smooth muscle cells. Cardiovasc Toxicol. 2016;16:251-259.

[32] Yuan B, Okusumi S, Yoshino Y, et al. Delphinidin induces cytotoxicity and potentiates cytocidal effect in combination with arsenite in an acute promyelocytic leukemia NB4 cell line. Oncol Rep. 2015;34:431-438.

[33] Zhang H, Guo Z-J, Xu W-M, et al. Antitumor effect and mechanism of an ellagic acid derivative on the HepG2 human hepatocellular carcinoma cell line. Oncol Lett. 2014;7:525-530.

[34] Malik A, Afaq S, Shahid M, et al. Influence of ellagic acid on prostate cancer cell proliferation: a caspase-dependent pathway. Asian Pac J Trop Med. 2011;4:550-555. 